\title{
Discours
}

Revue de linguistique, psycholinguistique et

informatique. A journal of linguistics, psycholinguistics

and computational linguistics

$10 \mid 2012$

Multidisciplinary Perspectives on Signalling Text

Organisation

\section{Children's Use of Comparative Text Signals: The Relationship between Age and Comprehension Ability}

Bonnie J.F. Meyer, Melissa N. Ray and Wendy Middlemiss

\section{OpenEdition}

\section{Electronic version}

URL: http://journals.openedition.org/discours/8637

DOI: $10.4000 /$ discours.8637

ISSN: 1963-1723

Publisher:

Laboratoire LATTICE, Presses universitaires de Caen

\section{Electronic reference}

Bonnie J.F. Meyer, Melissa N. Ray and Wendy Middlemiss, «Children's Use of Comparative Text Signals: The Relationship between Age and Comprehension Ability », Discours [Online], 10 | 2012 , Online since 16 July 2012, connection on 01 May 2019. URL : http://journals.openedition.org/ discours/8637 ; DOl : 10.4000/discours.8637

\section{(c) (i) (9)}

Discours est mis à disposition selon les termes de la licence Creative Commons Attribution - Pas d'Utilisation Commerciale - Pas de Modification 4.0 International. 

Revue de linguistique, psycholinguistique et informatique

\section{Children's Use of Comparative Text Signals:}

\section{The Relationship between Age and}

Comprehension Ability

Bonnie J.F. Meyer

The Pennsylvania State University

Melissa N. Ray

The Pennsylvania State University

Wendy Middlemiss

University of North Texas 



\section{Children's Use of Comparative Text Signals: The Relationship between Age and Comprehension Ability}

Bonnie J.F. Meyer

The Pennsylvania State University

Melissa N. Ray

The Pennsylvania State University

Wendy Middlemiss

University of North Texas

In this study we examined age differences in children and young adolescents' use of comparative text signals in order to gain insights into the development of signaling knowledge. We predicted that differential patterns of age differences would be found for readers classified as having low, middle, and high comprehension ability, and that the middle group of comprehenders would have the greatest amount of variability with age. $4^{\text {th }}, 6^{\text {th }}$, and $9^{\text {th }}$-grade readers' use of words employed to mark comparative relationships were compared by means of an open cloze. Results from analyses of competency of use scores, indicated that readers in the middle comprehension group had a larger number of significant increases in competency with age. Fewer age differences in overall competency were found for readers in low and high comprehension groups. Analysis of individual signals indicated that patterns of age differences may also vary in relation to the particular signal being processed. The findings from this study suggest that readers' overall comprehension ability may influence the acquisition and use of text signals.

Keywords: signaling, connectives, expository text, textual structures, text comprehension

\section{Introduction}

Signaling devices in text such as headings, preview statements, overviews, and logical connectives facilitate comprehension by directing readers' attention to text topics and their organization (Lorch, 1989; Meyer, 1975 and 1985a). They assist readers in the construction of a coherent mental representation. Coherence, the establishment of clear relationships among ideas remembered, is considered an essential indicator of text comprehension (Kintsch, 2004; Rapp et al., 2007; Van den Broek et al., 2004). Several studies have demonstrated the benefits of signaling. Reading texts with signaling devices has been associated with greater recall of ideas and a greater likelihood that the readers' organization of those ideas will closely align the author's (Kardash \& Noel, 2000; Loman \& Mayer, 1983; Lorch \& Lorch, 1985 and 1996a; Lorch, Lorch \& Inman, 1993; Mayer, Dyck \& Cook, I984; Meyer \& Poon, 200I; 
Meyer \& Rice, 1989; Ritchey, Schuster \& Allen, 2008). By providing explicit indices of importance and text structure, signals influence readers' ability to identify essential textual concepts and organize these ideas in a cogent manner.

Despite these benefits, the overall effectiveness of text signals may be constrained by the comprehension ability of the reader. While some researchers have found that both skilled and less skilled readers benefit from signaling (Loman \& Mayer, 1983; Kardash \& Noel, 2000), others have found that reading ability influences the effectiveness of text signals. Meyer, Brandt and Bluth (1980) found that while signaling did not benefit readers classified as highly skilled or low in skills, "underachievers", readers with high word reading ability but low comprehension skills, did benefit from signaling. Similarly, Naumann et al. (2007) found that while signaling did not have an effect on skilled readers' essays, less skilled readers produced essays with a higher quantity and quality of information when signaling was present. In examination of $5^{\text {th }}$-grade readers, Rossi (1990) found that both skilled and less skilled readers had higher comprehension test performance and produced better summaries when reading text with signaling. However, the relative benefits of different types of signaling (underlining of macrosentences, headings in texts, and headings in margins with underlining of macrosentences) varied in relation to readers' comprehension ability. While high comprehenders' performance only improved when macrosentences (main sentences) were underlined, low comprehenders had similar performance with all types of signaling investigated. Thus, while signaling benefited both groups of readers, skilled readers only benefited from certain signaling devices, suggesting that readers with higher comprehension were less reliant on text signals.

This variability in the benefit of signaling may reflect, in part, readers' need and ability to recognize signaling words and use them to organize their own understanding of a text. Highly skilled readers may possess a greater wealth of comprehension strategies, including mastery of structure strategies. Meyer, Brandt and Bluth (1980) suggested that readers who use a "structure strategy" approach texts with the goal of identifying and using the overall rhetorical text structure to organize their own understanding. Greater mastery of the strategy may then result in less need to rely on the presence of signals. These skilled readers may approach text with a structure strategy regardless of the presence of signaling. In contrast, readers with poor comprehension skills may not possess the strategies needed to make use of signaling (Meyer \& Rice, 1989). The middle group of comprehenders between these extremes may possess some understanding of strategies needed to make use of signaling, but not mastery of these strategies. Meyer et al. (1998) found that after initial structure strategy instruction, more proficient users of the structure strategy demonstrated use of the strategy six months later regardless of whether or not they read text with or without signaling of text structure. However, less proficient users of the strategy could only match the performance of the proficient students six months later when reading text with signaling (Meyer et al., 1998). Thus, there appears to be a group between high and low skilled readers with some understanding of signaling words and the structure strategy, but not mastery. 
The benefits of signaling may also be related to the challenge a text poses to a reader. In the studies with interactions between signaling and reading skills (Naumann et al., 2007; Meyer, Brandt \& Bluth, 1980), participants who benefited from signaling possessed reading strategies, but were confronted with texts that posed a challenge for them. On the other hand in the study by Loman and Mayer (1983), signaling aided participants regardless of reading skills; however, the readability of the texts (estimated difficulty in terms of grade levels or reading ease and often based on word frequency and sentence length) was adapted to participants' reading abilities. In their study, $\mathrm{IO}^{\text {th }}$-grade students with different reading skills read different texts, while the $9^{\text {th }}$-grade students in the Meyer et al. study all read the same texts. It is possible that when less skilled readers, like those in the Loman and Mayer study, are presented with texts more closely aligned with their current ability level, they may be better able to take advantage of signaling. Thus, the effects of readers' ability and readers' use of signaling may depend on the difficulty of the text.

Although several studies have examined adults' and adolescents' use of text signaling, children's use of signaling has been examined in relatively few studies. Some researchers have found that younger readers benefit from text signaling (Lorch et al., 200I; Ohlhausen \& Roller, 1988; Rossi, 1990), and evaluations of text structure interventions indicate that young readers' knowledge and use of signaling devices increase with instruction about the structure strategy (Meyer et al., 20Io; Meyer, Wijekumar \& Lin, 20II). Nevertheless, the lack of research with elementary and middle school readers makes it difficult to draw conclusions regarding the extent to which these readers make use of text signals.

Understanding children's sensitivity to signaling is particularly important in consideration of one current theory of signaling, SARA (Signaling Available, Relevant, and Accessible information) (Lemarié et al., 2008). According to Lemarié et al. (2008), signaling can serve multiple information functions, such as indicating the organization of text, providing emphasis, and denoting text topics. One of the determinants of readers' ability to benefit from signaling is accessibility, which refers to readers' abilities to "attend consistently" to information provided by signals and the "ease with which readers can use [this] information" in their processing of a text (Lemarié et al., 2008: 43). Unlike adults, children may still be developing comprehension skills and may lack the cognitive capacity to use signaling in text processing. Moreover, children may still be developing their knowledge of the function of signaling devices, including the ability to recognize the organizational relationships they describe. In order to understand the effect that signaling has on younger readers, it is important to investigate their knowledge of these signaling devices.

\subsection{Text structure signaling and connectives}

The current study explored individual differences in children's and young adolescents' knowledge of one type of signaling devices, text structure signaling words. Text structure signaling words are those words and phrases that explicitly denote the structural relationship among text propositions, as well as serve as indicators of the 
overall rhetorical structure of a text (Meyer, 1975 and $1985 \mathrm{~b})$. Meyer (1985b) proposed five major categories of signaling words/phrases: causation, collection (listing), comparison, description, and response (problem-and-solution). These categories reflect the expository text structures that they describe. The current study focused on young readers' knowledge of comparison text signaling words in the context of informational texts. When using the term knowledge, we refer to readers' abilities to recognize and use appropriate signaling words. Comparison signaling words were chosen because comparative relationships may present a challenge to young readers, particularly in relation to the less difficult collection relationships (Englert \& Hiebert, 1984). In order to examine individual differences for the current study, it was important to select a structure that readers had not already mastered.

Text structure signaling words are similar to logical connectives (also referred to as coherence markings) and conjunctions. Logical connectives are words and phrases that serve as explicit markers of coherence, expressing the nature of the relationship between and among textual ideas (Degand \& Sanders, 2002; Sanders, 1997; Spooren $\&$ Sanders, 2008). Sanders and colleagues (e.g. Sanders, Spooren \& Noordman, 1992; Sanders, 1997) have proposed a taxonomy of coherence relationships and their connectives that consists of two basic functions, additive and causal, and several different dimensions such as polarity, ordering, and goal (semantic vs. pragmatic). Conjunctions are similar to logical connectives; both explicitly indicate relationships. Halliday and Hasan (1976) classified cohesive relationships and their conjunctions into four general types: additive, adversative, temporal, and causal. Unlike the connectives described by Sanders and colleagues, Halliday and Hasan's definition of conjunctions is focused on the text itself, rather than on the underlying ideas represented by the text.

Although signaling words and conjunctions share some similarities, there are key differences between the conjunctions classified by Halliday and Hasan (1976) and the signaling words described by Meyer ( 1975 and $1985 \mathrm{a}$ ). Meyer's classification is broad; it includes more structural relationships and classifies more textual elements as signaling words beyond conjunctions and adverbial phrases. Although Halliday and Hasan (1976) and Meyer (1975 and 1985a) include a category for comparative relations, the nature of the category is different. Halliday and Hasan's comparative category, adversative, focuses solely on contrasting relationships. Adversative conjunctions link two propositions, one of which expresses a refutation or a departure from the expectation presented in the other. Meyer's comparison category of signaling words include words and phrases which indicate both similarities and differences, rather than just differences. Moreover, the adversative (contrastive) relationships expressed by comparison signaling words are much broader and include the introduction of differences (e.g. on the other hand, unlike) among a list of compared entities. According to the Halliday and Hasan categorization, conjunctions serving these purposes would be considered additive relations. Although conjunction research based on Halliday and Hasan's classification can inform conclusions about children's knowledge of signaling words, these conclusions should be made cautiously given the differences between their classification and Meyer's. 


\subsection{Children's knowledge of connectives}

Previous research suggests that children have knowledge of connectives at fairly young ages and that this knowledge increases with age (Cain, Patson \& Andrews, 2005; Geva \& Ryan, 1985; Peterson, 1986) and reading ability (Bridge \& Winograd, 1982; Cain, Patson \& Andrews, 2005; Geva \& Ryan, 1985; Zinar, 1990). Knowledge of connectives may develop in relation to the type of relationship. Certain connectives, specifically additive relations, may be acquired before other more complex relationships like causals (Cain, Patson \& Andrews, 2005; Cain \& Nash, 20II; Spooren \& Sanders, 2008). This continuum of acquisition is also reflected in studies of children's knowledge of text structure, which suggests that less structured relationships like a collection of descriptions are mastered before more structured organizations like causation (Richgels et al., 1987).

Regarding comparative relationships, Cain, Patson and Andrews (2005) found that children's knowledge of adversatives, as measured by cloze tasks, was similar to knowledge of additive relations and greater than temporal and causal relationships. Nevertheless, performance on adversative, but not additive, connectives significantly increased with readers' age (Cain, Patson \& Andrews, 2005). This suggested that although contrasts may not present the challenge that causal relations do, readers continue to improve in their ability to use these words. Similarly, Peterson (1986) found that while both younger and older children produced "but" in oral narratives, older readers made fewer errors and used the conjunction in more complex ways.

In regard to children's use of connectives in relation to adults' use, research findings are somewhat mixed. Cain and Nash (20II) found that Io-year-olds performed similarly to adults on a coherence judgment task. However, this similarity in performance was qualified by the type of connective, with Io-year-old children having similar performance on some relationships (e.g. adversatives) but not others. Other researchers have found that children use these words in qualitatively difference ways from adults (McClure \& Geva, 1983), suggesting that while children have knowledge of these words, they lack the sophistication of adults' usage.

Overall, previous research suggests that school-age children should have knowledge of comparison signaling words and should be able to identify when a comparison word or phrase is needed. However, their expertise in using these signaling words may still be developing, and as a result, it is possible that accurate use of text structure signaling words will increase with age, particularly for those connectives which signal complex relationships. This may be especially true when readers are asked to generate the signaling words, rather than select a choice, as generation tasks may be more challenging than choice tasks (Cain, Patson \& Andrews, 2005). Moreover, using signaling words with expository texts may present more of a challenge, as readers may have less experience with reading expository texts (Duke, 2000). Although several studies have investigated the use of connectives in narrative contexts (both oral and written), few studies have examined knowledge of these words in expository texts (e.g. Zinar, 1990). Research conducted with adults has found that the effect of connectives may vary in relation to text genre 
(Kamalski, Sanders \& Lentz, 2008). It is possible that while readers demonstrate competence in using signals in narrative contexts, abilities to use these same words in an informational context may still be developing.

\section{Focus of the current study}

The goal of the current study was to examine age differences in elementary and middle school readers' knowledge of comparison text structure signals in order to gain insights into the development of signaling knowledge. We sought to answer two central research questions: I) Does knowledge of comparison signaling words increase with age (as measured by grade)? 2) Does overall comprehension ability moderate this increase? In other words, do readers of varying comprehension ability demonstrate different developmental patterns in knowledge of signals? We examined $4^{\text {th }}-, 6^{\text {th }}$-, and $9^{\text {th }}$-grade students' knowledge of comparison text signals through the use of a cloze task. Cloze tasks have frequently been used to measure knowledge and use of connectives (Cain, Patson \& Andrews, 2005; Cain \& Nash, 20II; Geva \& Ryan, 1985; Zinar, 1990). Unlike these studies, however, we employed an open cloze, in which readers were asked to generate a signaling word rather than selecting a word/phrase from a given list of choices. This type of cloze was used in order to answer questions regarding the extent and quality of readers' signaling knowledge. By eliciting reader-generated responses, we hoped to capture not only readers' ability to produce a target-like response, but also readers' level of competence in using signaling. In relation to competency, we were interested in the degree to which readers could generate signaling words that matched both the semantic and syntactic constraints of the text.

Although both age and overall comprehension ability have been considered in previous connectives research, few studies have examined these predictors jointly. Consideration of both of these factors is important because readers' overall comprehension ability may influence the development of text processing skills. In a longitudinal study of children's text processing skills, Vauras, Kinnunen and Kuusela (1994) found that readers' initial comprehension abilities predicted their growth in coherence building processes; highly skilled readers had greater gains than readers who were classified as less skilled. This influence is similar to a Matthew effect (Stanovich, 1986), in which the difference between skilled and less skilled readers increases over time due to the quality and quantity of their reading experiences. In contrast, in a study of reading achievement in middle school students, Rescorla and Rosenthal (2004) found that differences among readers initially classified as skilled and less skilled decreased over time. Their findings suggest that for young adolescents, overall reading ability has a greater impact on growth for less skilled readers, rather than skilled. Still other researchers have failed to find any influence of overall comprehension ability, finding that skilled and less skilled readers made comparable gains (Shaywitz et al., 1995). Taken together, these studies suggest that the relationship between age and reading ability may be complex, and the extent to which overall comprehension ability influences age differences remains unclear. 
In relation to the development of signaling word knowledge, we predicted that knowledge would increase from earlier to later grades. Although previous research supports increases in knowledge of text structure signaling, some research (e.g. Cain \& Nash, 20II) has suggested that readers acquire the ability to use these words during elementary school. Thus, it is possible that while knowledge increases with age, signaling word knowledge will maximize at a certain age, after which little improvement would occur. We believed that the generation task would assess a deeper level of knowledge than that measured by choice tasks, and as a result, increases in knowledge would be found from the lower to higher grades.

In establishing hypotheses regarding the relationship between age and comprehension ability, we relied on previous research of younger readers' sensitivity to signaling devices in general. Following the approach of Meyer, Brandt and Bluth (1980), we used the same text materials for different ability groups to control for variability in text characteristics. Previous research that used the same texts for all reading abilities, suggests that the middle group of readers is most variable in proficient use of strategies related to signaling (Meyer, Brandt \& Bluth, I980). The materials used in this study were written at an upper $5^{\text {th }}$ - to $6^{\text {th }}$-grade level and as such the variability in challenge would be greatest for the middle ability readers at all grade levels. For this middle ability level of readers, we expected to see greater changes over the grades with increasing proficiency in signaling word use.

The most proficient readers across the grades were expected to show less variability in performances than middle ability readers. Previous research of children's knowledge of connectives has suggested that younger readers may acquire signaling word knowledge at an early age. We predicted that less variability among higher ability readers may be due to early mastery of text structure signaling words among this group. Low ability readers across the grades were expected to have few reading comprehension strategies related to text structure and less variable performance across grades. Additionally, the text and task may be too challenging at all grade levels for low-skill readers. Thus, we predicted an interaction between reading comprehension ability and grade level on the cloze tasks, in which patterns of age difference varied in relation to readers' overall comprehension skill.

\section{Method}

\subsection{Participants}

Participants consisted of 360 students from the same school district in a small northeastern US city: I2I $4^{\text {th }}$, $1586^{\text {th }}$, and $819^{\text {th }}$-graders participated. Students ranged in age from 9.0 to 16.0 years [ $4^{\text {th }}$-grade $M=9.08,6^{\text {th }}$-grade $M=11.96,9^{\text {th }}$-grade $M=14.84]$. The $4^{\text {th }}$ - and $6^{\text {th }}$-graders attended one of the district's elementary schools, while all of the district's $9^{\text {th }}$-grade students attended one combined middle and high school. Participants were classified into one of three comprehension ability groups: low, middle, and high on the basis of performance on a standardized test of reading 
comprehension administered at the beginning of the study (Gray Silent Reading Test [GSRT]; Wiederholt \& Blalock, 2000). The GSRT is a multiple choice test in which students answer questions about thirteen passages of increasing difficulty (form reliability is .95). Table I contains GSRT scores for each grade. Within each grade, students were grouped according to z-scores calculated from students' raw scores. Students with $\mathrm{z}$-scores of 0.55 or higher were placed into the high group; readers with scores between -0.55 and 0.55 were placed into the middle group and readers with $\mathrm{z}$-scores of -0.55 or lower were classified as low.

\begin{tabular}{|c|c|c|c|c|c|c|c|c|}
\hline Grade & Age & & Raw GSP & & G.E. GSI & & A.E. GS & \\
\hline & $M$ & $S D$ & $M$ & $S D$ & $M$ & $S D$ & $M$ & $S D$ \\
\hline 4 & 9.80 & $0.5 \mathrm{I}$ & 25.20 & II. 37 & 4.I6 & 2.76 & IO.OI & 2.74 \\
\hline 6 & II.97 & 0.52 & 34.18 & $\mathrm{I} 3.43$ & 6.63 & 3.78 & 12.49 & 3.80 \\
\hline 9 & I4.84 & 0.58 & 43.65 & 13.02 & $9 \cdot 46$ & 3.57 & 15.33 & 3.60 \\
\hline
\end{tabular}

Table 1. Raw, grade equivalent, and age equivalent scores on GSRT ${ }^{1}$

\subsection{Procedures}

Students completed experimental tasks within intact classrooms during the school day. The data collected in this study were part of a larger study examining school-age children's knowledge of expository text structures and measures for assessing this knowledge. Most students completed all study materials during one session; however due to scheduling problems some students $(n=63,17.5 \%)$ completed the reading comprehension test (GSRT) in a separate session. All texts and tasks were contained within a written packet of material, which also included instructions for each task. In addition to the comparison texts, students also read problem-and-solution texts, which did not contain signaling cloze, and were not analyzed as part of the current study.

\subsection{Cloze task and texts}

For the cloze task, six comparison texts were generated. Three comparison texts were designed to be equivalent. These texts contained similar topics involving the comparison of two types of the same animal (turtles, primates, penguins) on several issues including: size, appearance, diet, and habitat. All animals were compared on the same issues. Other texts were created by adapting passages from a $5^{\text {th }}$-grade social sciences textbook (Berson, 2003). These texts were historical in nature and included topics such as the American Revolution and Mount Rushmore. The cloze tasks associated with these texts were not included in the current study. In order to make judgments of signaling knowledge, we wanted to hold text factors as consistent as possible. Previous studies have shown that the effectiveness of signaling may vary as a function of text familiarity, complexity, and length (Lorch, Lorch \& Inman, I993;

1. G.E. = grade equivalent, A.E.= age equivalent. 
Lorch \& Lorch, 1996b). The excluded historical texts varied considerably in length (97 to I82 idea units) and readability (Flesch Kincaid grade levels: 7.I to 9.0) from both one another and the equivalent comparison texts. Because we were interested in issues related to reader characteristics, we wanted to minimize the possibility that textual differences could influence outcomes.

The equivalent texts were each short 2-paragraph texts of I26 words. Each text was parsed according to Meyer's (1985b) method of content analysis, and contained the same number of propositional idea units (9I units). The readability of these texts was similar, Flesch-Kincaid grade levels (Flesch, 1948; Test Your Document's Readability, 2007) ranged from 5.4 to 6.I. Each text contained the same four comparative signaling words, "different", "unlike", "smaller/larger", and "same as". These words appeared in the same locations within each text. Figure I contains one of the cloze passages used (penguins). For the primate text, the word "larger" rather than "smaller" was used to introduce a size difference between the animals, as the bigger primate was discussed after the smaller. For the other two passages, the larger animal was discussed first. In order to generate each cloze, these words were deleted from each of the text and replaced with a blank. No other conjunctions/connectives in the text were manipulated.

Emperor penguins and Adelie penguins are from one another. Emperor penguins are the largest of all the penguins. They may grow up to 4 feet tall and can weigh more than 90 pounds. They have yellow necks and long beaks. Emperor penguins live in icy Antarctica. The emperor penguins feed mainly on fish and squid. the large emperor penguins, Adelie penguins are some Adelie penguins grow only about 2 feet high and others reach 3 feet. An Adelie penguin has a short beak and feathers that cover most of it. They have no feathers on the tips of their beaks. Adelie penguins feed almost entirely on krill, which are part of crustaceans. The as emperor penguins, Adelie penguins live in icy Antarctica.

Figure 1. Penguin cloze

The equivalent texts on the three topics were counterbalanced to appear as the second, fifth, or final tasks in the packet, resulting in three orders. Students were randomly assigned to one of these three orders. Immediately prior to the first comparison text, students were given a short practice item. The example cloze used description/collection signaling words (also, in summary) rather than comparison so as not to influence performance on the signaling tasks. Students were instructed to complete the texts by writing an appropriate word into each blank and were then asked to write a good main idea of less than two sentences for the text. An example response appeared after the sample item, demonstrating the correct answer for the cloze responses as well as providing a sample main idea. Before reading the first comparison text, written instructions were repeated. Instructions did not specifically ask students to provide "signaling words" or "conjunctions". Students' main ideas were not analyzed as part of this study. 


\subsection{Missing data}

Students were asked to complete several reading tasks within one session. As a result, several students $(n=56,15 \%)$ did not complete the final task in the packet, which was one of the equivalent comparative texts. Due the large amount of missing data, only the responses for the first two equivalent comparative texts were analyzed. All other incomplete items received a score of o. Due to random assignment of the three text topics to the three orders: second, fifth, and final tasks in the packet, about a third of each topic appeared on the second and fifth task. There were no significant interactions between order/topic and the factors of interest in this study, comprehension ability and grade. The dependent measure (signaling competency) was summed over performance on the parallel texts from the second and fifth tasks, and order/topic will not be considered further in this study.

\subsection{Scoring}

In order to measure readers' knowledge of comparative text signals, each response was scored using a competency of use scale. The signaling competency scale, developed by Meyer and colleagues (e.g. Meyer et al., 2oIo; Meyer, Wijekumar \& Lin, 20II), is designed to measure readers' degree of expertise in using signaling words and phrases. Specifically, the scale evaluates the extent to which readers produce the target response. Scores on the scale ranged from $\mathrm{I}^{-7}$, with scores of $3^{-7}$ indicating that a signaling word was produced, and scores of 5-7 indicating that a signaling word was used that expressed the correct comparative relations. In order to receive a score of 7 , readers had to produce the target. Responses received scores of $\mathrm{I}-2$ to indicate use of a non-signal, content word. The internal consistency of the signaling competency scale, calculated by using Cronbach alpha, was 0.82 .

Students received two types of scores. The first, a total signaling competency score measured students' overall knowledge of comparative signaling. Total scores were calculated by summing across all responses for both comparison texts ( 56 points total). Students also received individual signaling word competency scores. Word scores were calculated in order to determine whether knowledge of signaling words varied across different types of signaling words. We created a score for each signaling word/phrase ("different", "unlike", "smaller/larger", "same as"), by summing ratings for each type of signaling word across both passages, resulting in four word scores (a total of I4 points possible for each).

\section{Results}

\subsection{Overall signaling competency}

In order to analyze readers' overall signaling competency, a two-factor ANOVA was conducted on total signaling competency scores with grade $\left(4^{\text {th }}, 6^{\text {th }}\right.$, and $\left.9^{\text {th }}\right)$ and comprehension group (low, middle, and high) as predictors. For all statistical tests alpha was set at 0.05 , and exact $p$ values are reported, except when $p<.00$. 
Analyses revealed a main effect for grade, $F(2,35 \mathrm{I})=15.40, p<.00 \mathrm{I}, \eta^{2}=0.08$, and reading group, $F(2,35 \mathrm{I})=29.82, p<.00 \mathrm{I}, n^{2}=.14$, as well as a significant grade $\mathrm{x}$ reading group interaction, $F(4,35 \mathrm{I})=3.66, p=.006, n^{2}=0.04$. Table 2 contains total competency scores for each grade. Post-hoc comparisons for grade levels were conducted using Tukey HSD. Competence of signaling use increased with grade; $6^{\text {th }}$-graders and $9^{\text {th }}$-graders had higher signaling competency scores in comparison to $4^{\text {th }}$-graders, $p<$.ooI. Although $9^{\text {th }}$-graders tended to have higher competency scores than $6^{\text {th }}$-graders, this increase was not significant, $p=. I 14$. Because the effect of grade was qualified by a grade $\mathrm{x}$ reading group interaction, we examined the effect of grade within the high, middle, and low comprehension ability groups (see Figure 2).

\begin{tabular}{|c|c|c|c|c|}
\hline & $\begin{array}{l}\text { Comprehension } \\
\text { group }\end{array}$ & $n$ & $M$ & $S D$ \\
\hline \multirow[t]{4}{*}{ Grade 4} & I & 32 & 18.22 & 8.02 \\
\hline & 2 & 54 & 2I.II & 8.93 \\
\hline & 3 & 35 & 30.17 & 9.33 \\
\hline & $M$ & I2I & 22.97 & 9.96 \\
\hline \multirow[t]{4}{*}{ Grade 6} & I & $5 \mathrm{I}$ & 25.75 & I 4.73 \\
\hline & 2 & 50 & 28.88 & 9.12 \\
\hline & 3 & 57 & 34.98 & I2. 78 \\
\hline & $M$ & 158 & 30.07 & I2.99 \\
\hline \multirow[t]{4}{*}{ Grade 9} & I & I8 & 19.78 & II. 72 \\
\hline & 2 & 42 & 36.33 & $\mathrm{I} 2.48$ \\
\hline & 3 & $2 \mathrm{I}$ & 38.57 & I6.OI \\
\hline & $M$ & $8 \mathrm{I}$ & 33.23 & 15.04 \\
\hline
\end{tabular}

Table 2. Total signaling competency by grade and comprehension group ${ }^{2}$

Tests of simple main effects indicated a significant main effect for grade for the low, $F(2,98)=4.04, p=.021, n^{2}=.08$, middle, $F(2,143)=26.85, p<.001, n^{2}=.27$, and high reading groups, $F(2$, IIO $)=3.20, p=.044, n^{2}=.05$. For the low comprehension ability group, $6^{\text {th }}$-graders had significantly higher scores than $4^{\text {th }}$-graders, $p=.023$. There were no other significant grade differences in signaling competency scores for the low comprehension group. For the middle group of comprehenders, $6^{\text {th }}$-graders had higher scores than $4^{\text {th }}$-graders, $p<$.ooI. $9^{\text {th }}$-graders had higher scores than both $6^{\text {th }}-(p=.002)$ and $4^{\text {th }}$-graders, $p<.001$. Although there were grade increases in

2. $\quad \mathrm{I}=$ low, 2 = middle, $3=$ high . 
signaling competency within the high ability group, the only significant difference between grades, was between $9^{\text {th }}$ and $4^{\text {th }}$-graders, with $9^{\text {th }}$-graders having higher competency scores than $4^{\text {th }}$-graders, $p=.044$.

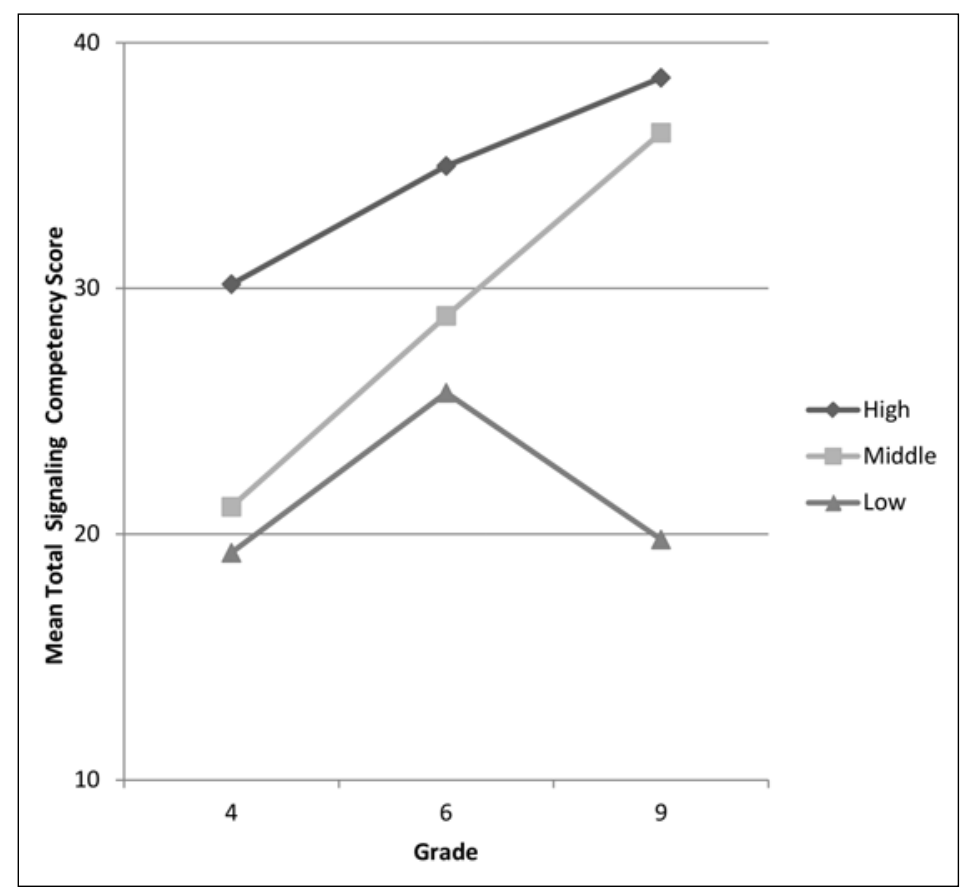

Figure 2. Total signaling competency scores for low, middle, and high comprehension groups

\subsection{Competency for individual signals}

In order to examine the effect of grade and comprehension ability on competency using particular comparison signals, a multivariate analysis of variance (MANOVA) was conducted on word signaling competency scores ("different", "unlike", "smaller/ larger", "same as"). Multivariate tests indicated a significant effect for grade, $F(8$, 696) $=7.09, p<.001, n^{2}=0.07$, and comprehension skill $F(8,696)=9.00, p<.001$, $n^{2}=0.09$. Univariate ANOVAs were conducted for each of the four words separately. Table 3 contains descriptive statistics for each signaling word at each grade by reading ability level.

For the word "different", there was a significant main effect for reading group, $F(2,35 \mathrm{I})=17.39, p<.00 \mathrm{I}, n^{2}=.09$, but no main effect for grade, $F(2,35 \mathrm{I})=\mathrm{I} .4 \mathrm{O}$, $p=.247, n^{2}=$. oI. The grade by reading group interaction was not significant, $F(4$, $35 \mathrm{I})=\mathrm{I} .78, p=.132, n^{2}=.02$. Readers in the high $(M=12.67, S D=3.24)$ and middle $(M=11.76, S D=3.86)$ comprehension groups had significantly higher competency scores for using "different" than readers in the low group $(M=9.53, S D=4.95)$, $p<$ oo I. However, the difference between the high and middle comprehension 
groups was not significant, $p=.094$. Signaling competency scores were significantly higher for "different" than for the other three signaling words ( $p<$. .OoI).

\begin{tabular}{|c|c|c|c|c|c|c|c|c|c|}
\hline & & \multicolumn{2}{|c|}{ Different } & \multicolumn{2}{|l|}{ Unlike } & \multicolumn{2}{|c|}{ Smaller/Larger } & \multicolumn{2}{|c|}{ Same as } \\
\hline & & $M$ & $S D$ & $M$ & $S D$ & $M$ & $S D$ & $M$ & $S D$ \\
\hline \multirow[t]{4}{*}{ Grade 4} & I & 9.34 & $4.5^{8}$ & 2.66 & 2.03 & 3.19 & 2.19 & 3.03 & 3.53 \\
\hline & 2 & 10.50 & 4.67 & 2.74 & 2.08 & 4.39 & $3.0 \mathrm{I}$ & 3.48 & 3.44 \\
\hline & 3 & I2.97 & 2.63 & 3.94 & 2.93 & 5.94 & 3.93 & $7 \cdot 3 \mathrm{I}$ & $5 \cdot 47$ \\
\hline & $M$ & I0.9I & 4.36 & 3.07 & 2.39 & 4.52 & 3.27 & $4 \cdot 47$ & 4.50 \\
\hline \multirow[t]{4}{*}{ Grade 6} & I & IO.I4 & 4.92 & 5.04 & 4.09 & 5.57 & 4.15 & 4.92 & 4.73 \\
\hline & 2 & $\mathrm{I} 2.26$ & 3.85 & 4.80 & 3.52 & 7.14 & 3.84 & 4.68 & $4 \cdot 14$ \\
\hline & 3 & I2.77 & 3.48 & 7.02 & 4.23 & 8.33 & $4 \cdot 42$ & 6.86 & 4.83 \\
\hline & $M$ & II. 76 & 4.24 & 5.68 & 4.07 & 7.06 & 4.29 & 5.54 & 4.67 \\
\hline \multirow[t]{4}{*}{ Grade 9} & I & 8.94 & 4.56 & 3.78 & 3.80 & 4.06 & 3.80 & 3.00 & 3.69 \\
\hline & 2 & 13.00 & 2.24 & $7 \cdot 57$ & 4.45 & 9.02 & 4.33 & 6.74 & 5.08 \\
\hline & 3 & I2.86 & 3.09 & 8.76 & 6.07 & 9.38 & 5.12 & $7 \cdot 57$ & $4.8 \mathrm{I}$ \\
\hline & $M$ & I2.06 & 3.49 & 7.04 & 5.07 & 8.oI & 4.88 & 6.12 & 4.99 \\
\hline
\end{tabular}

Table 3. Signaling competency for each word by grade and comprehension group ${ }^{3}$

For the word "unlike", there was a significant main effect for reading group, $F(2,35 \mathrm{I})=\mathrm{I} 2.39, p<.00 \mathrm{I}, n^{2}=.066$, and grade, $F(2,35 \mathrm{I})=24.24, p<.00 \mathrm{I}, n^{2}=0.12$, which was qualified by a significant grade by reading group interaction, $F(4$, $35 \mathrm{I})=2.96, p=0.020, n^{2}=.033$. Analyses of simple main effects indicated that there was a significant effect for grade for low, $F(2,98)=4.59, p=.012, n^{2}=.09$, middle, $F(2, \mathrm{I} 43)=23.94, p<.00 \mathrm{I}, n^{2}=0.25$, and high ability groups, $F(2, \mathrm{IIO})=9.48, p<.00 \mathrm{I}$, $n^{2}=$. oI5. A post-hoc comparison of grades revealed varying patterns of age differences within each reading group. For the low comprehension group, the only significant difference was between the $6^{\text {th }}$ and $4^{\text {th }}$-graders, $p=.009$, with $6^{\text {th }}$-graders receiving higher competency scores. For the middle ability group, a significant increase in ratings was found across all groups with $6^{\text {th }}$-graders having higher scores than $4^{\text {th }}$-graders, $p=.007 .9^{\text {th }}$-grade readers in the middle group had higher scores than both $6^{\text {th }}$ - and $4^{\text {th }}$-graders, $p<$. oor. For the high comprehension ability group, both $6^{\text {th }}$ - and $9^{\text {th }}$-graders had higher performance than $4^{\text {th }}$-graders, $p=.003 .9^{\text {th }}$-grade, high ability readers also had higher scores than $4^{\text {th }}$-grade, $p<$. ooI, but the difference

3. Comprehension group: $\mathrm{I}=$ low, $2=$ middle, 3 = high 
between $6^{\text {th }}$ - and $9^{\text {th }}$-grades in the high group was not significant, $p=.254$. Figure 3 displays the grade means and significant interaction for "unlike".

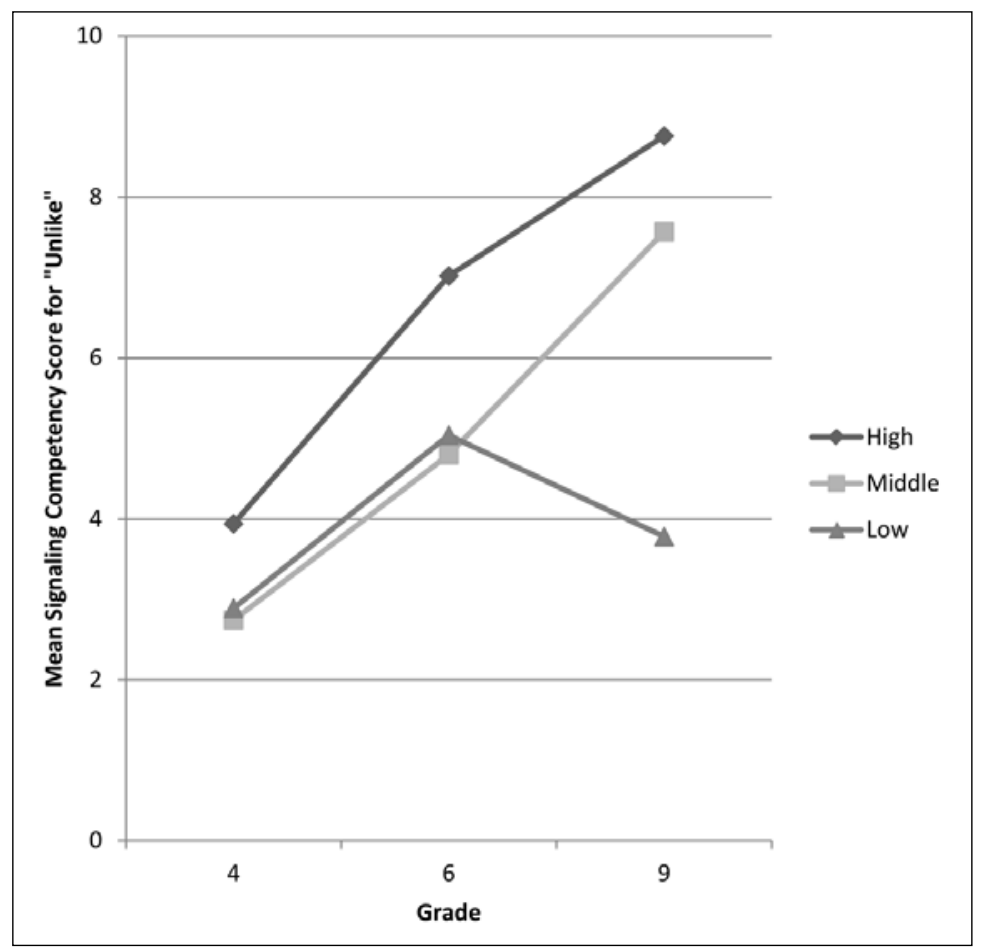

Figure 3. Signaling competency scores for "unlike" for low, middle, and high comprehension groups

For the word "smaller/larger", there was significant main effect for reading group, $F(2,35 \mathrm{I})=20.34, p<.00 \mathrm{I}, \eta^{2}=0.10$, and grade, $F(2,35 \mathrm{I})=17.95, p<.00 \mathrm{I}, \eta^{2}=0.09$. However, the interaction between reading group and grade was not significant, $F(4$, $35 \mathrm{I})=2.10, p=.08 \mathrm{I}, n^{2}=0.02$. A comparison of grades revealed that both $9^{\text {th }}$ - and $6^{\text {th }}$-graders had significantly higher competency scores in comparison to $4^{\text {th }}$-graders, $p<.00 \mathrm{I}$; but the difference between $6^{\text {th }^{\mathrm{t}}}$ - and $9^{\text {th }}$-graders was not significant, $p=.179$.

For the phrase "same as", the main effect for reading group, $F(2,35 \mathrm{I})=15.19$, $p<.00 I, n^{2}=.08$, was significant while the main effect for grade, $F(2,35 \mathrm{I})=\mathrm{I} .87, p=.155$, $n^{2}=$.oII, was not. There was a significant grade by reading group interaction, $F(4$, $35 \mathrm{I})=2.59, p=.038, n^{2}=.03$ (see Figure 4 ). An examination of simple main effects, revealed a main effect for grade for only the middle group of readers, $F(2, \mathrm{I} 43)=7.14$, $p=.001, n^{2}=.09$. There was no significant main effect for grade for the low and the high comprehension groups. A comparison of grades within this middle group indicated that $9^{\text {th }}$-graders had significantly higher competency scores than $4^{\text {th }}$-graders, $p=$. oor. There were no other significant differences between the grades within the middle group. 


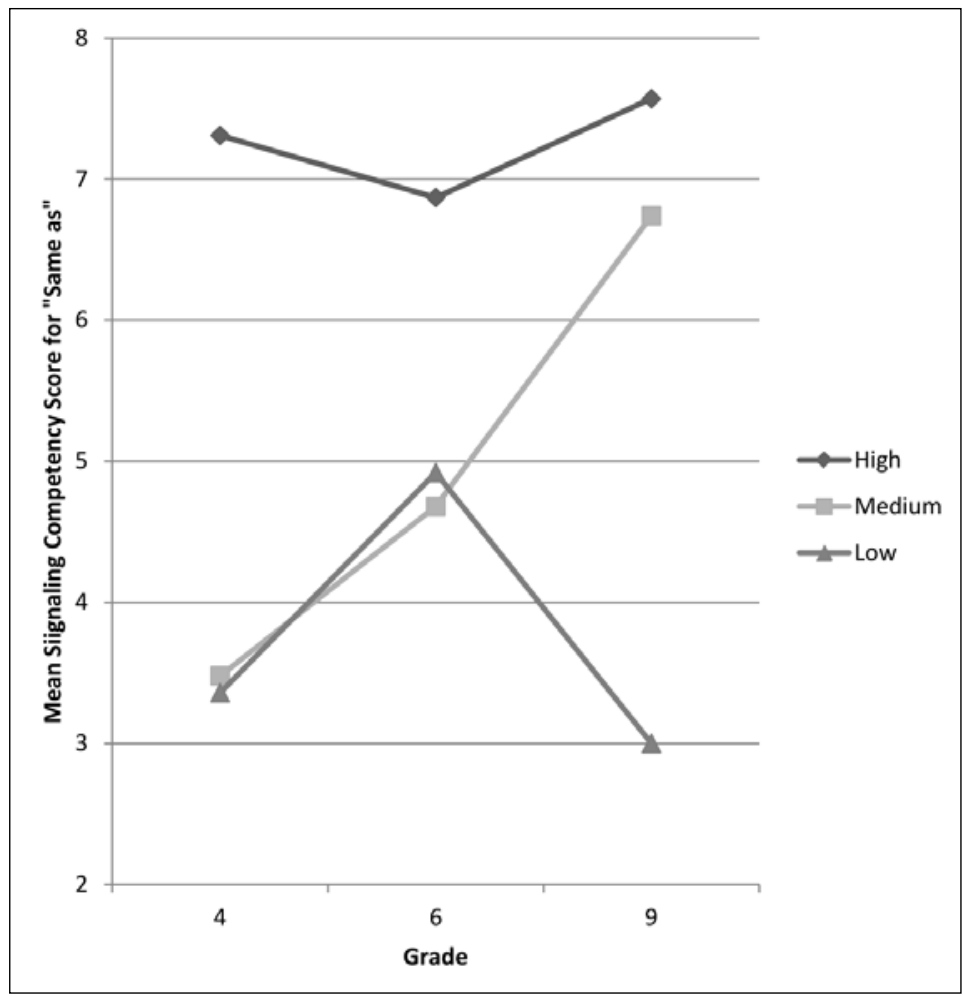

Figure 4. Signaling competency scores for "same as" for low, middle, and high comprehension groups

\section{Discussion}

We hypothesized that although signaling knowledge would increase with age, this increase would be influenced by the overall comprehension ability of the reader. Readers of varying overall comprehension skill levels would have differential developmental patterns, which would reflect the role that comprehension skill plays in the use of signaling. We predicted that readers of high and low comprehension ability would have the least amount of variability with age, while middle ability readers would have the most variability and growth with age. With regard to overall knowledge of comparison signaling, readers' overall comprehension ability influenced age differences in patterns similar to those predicted for low, middle, and high comprehension skill groups.

For low reading comprehension ability students few grade differences were found; the only significant increase with age was the higher signaling scores of $6^{\text {th }}$-grade in comparison to $4^{\text {th }}$-grade. $6^{\text {th }}$-graders also had better performance than $9^{\text {th }}$-graders, although this difference was not significant $(p=0.192)$. For this group of readers, the oldest students, $9^{\text {th }}$-graders, demonstrated signaling knowledge similar to the youngest, $4^{\text {th }}$-graders. It is possible that this finding reflects less variability 
in signaling word knowledge among low skill readers. This low variability across grades, coupled with a lower performance overall for this group, suggests their lower comprehension skills may inhibit their ability to develop knowledge of these words.

For readers in the high comprehension ability groups, there were also few significant increases with age. The only significant increase with age in overall quality of signaling competency was between the oldest readers, $9^{\text {th }}$-grade, and the youngest readers, $4^{\text {th }}$-grade. For highly skilled readers, signaling knowledge was fairly stable across all grades. Given the higher competency scores of this group, it appears that highly skilled readers achieve knowledge of comparison signals at a fairly young age. For these readers few age differences may be the result of a maximization of comparative signaling knowledge. However, without an adult comparison group, it is difficult to determine whether these readers had achieved adult-like competency.

In terms of overall knowledge of comparison signaling, the middle comprehension group had the most consistent increases in signaling competency with grade. Significant increases in the generation of comparative signaling words were found at both $6^{\text {th }}$ - and $9^{\text {th }}$-grades. As predicted, the middle reading comprehension skill group had more significant increases in signaling with age than both high and low skill comprehenders. Unlike readers in the high ability group, it does not appear that signaling knowledge maximizes for this group of readers, rather steady increases can be found across grades. At $4^{\text {th }}$-grade, average readers had significantly lower scores in comparison to highly skilled readers $\left(p<\right.$. .oooI), however, at $9^{\text {th }}$-grade, the difference between middle and high ability groups was not significant $(p=.805)$. This pattern suggests that at younger ages, differences among these two ability groups may be larger than at older ages. The opposite pattern emerged for middle and low skilled readers. At $4^{\text {th }}$ and $6^{\text {th }}$-grades, the difference between these groups was not significant $(p=.309$ and $p=.418$, respectively). In comparison, at $9^{\text {th }}$-grade, the middle comprehension ability group had significantly higher competency scores in comparison to the low group $(p<$. .OoI). With additional years of schooling and increased exposure to expository texts, average readers may make steady gains in their use of signaling words, eventually achieving competency similar to that of highly skilled readers. Unfortunately, we did not collect data on readers in grades higher than $9^{\text {th }}$-grade, but it is possible that average readers experience similar maximizing of signaling knowledge as found with skilled readers. The data shown for $9^{\text {th }}$-grade in Table 3 in the bottom rows under "different" suggest that this may be happening for the easiest comparative signaling word in this study.

Three different developmental patterns emerged for the low, middle, and high comprehension groups. These patterns share some similarities with those found in previous comprehension research. Readers with low levels of comprehension skills had consistently lower competency in using signaling words, in comparison to the highly skilled readers. Similar to Vauras, Kinnunen and Kuusela (1994), there was little difference among grade levels for the low ability group. Unlike Vauras, Kinnunen and Kuusela (1994), there were also few significant improvements with age for the high comprehension ability group. This difference in findings may be 
because signaling knowledge is one component of a larger array of comprehension processes in which readers engage. As a result the complexity involved in acquiring signaling knowledge may be less than overall text processing, which involves the coordination of numerous processes. While skilled readers appear to have early acquisition of comparison signals, readers with low comprehension skills consistently have more difficulty using comparison signals.

Readers in the middle comprehension group had consistent increases with age. Moreover, at lower grades these readers were more similar to less skilled readers, while at later grades they were more similar to highly skilled readers. This developmental pattern is somewhat similar to Rescorla and Rosenthal's (2004) findings of decreased differences between readers at later grades. This pattern also suggests that average readers move from relatively low competency to relatively high competency with age. Overall, the different patterns of age differences for each reading ability group in this study point to the importance of accounting for comprehension ability in future studies about younger readers' sensitivity and use of signaling.

\subsection{Knowledge of individual signals}

An examination of individual comparison signals suggests that the influence of comprehension ability on signaling knowledge development may vary in relation to the signal itself. For the word "different", there were no significant age differences, and performance on this particular word was higher than performance on the other signal words. It is possible that competency in using some signaling words is acquired early, and that these words are fairly easy to use, while other signaling words pose more of a challenge to readers.

In the case of the word "different", this word identified the most basic comparative relationship expressed in the passage and the overall topic of the passage (two animals that are different from one another). When the comparative relationship is relatively more salient, readers may be more able to identify and express the comparative relation. In contrast, the other words, "unlike", "smaller/larger", "same as", were all contained in sentences that described a particular point of comparison, in which the comparative relationships expressed were more specific and complex. Moreover, contrary to the word "different" the other signal words were contained in points of comparison located lower in the hierarchical structure of the text. Readers' abilities to produce these words may be more greatly influenced by their overall structural knowledge. Younger and less skilled readers' ability to perceive and use the comparative text structure is still developing (Englert \& Hiebert, 1984; Meyer, Brandt \& Bluth, 1980). Thus, those signals that are more reflective of readers' abilities to use a "structure strategy," such as comparing two animals on a number of parallel specific issues, will also have more variability in terms of age.

For both "unlike" and "same as" a significant comprehension ability by grade interaction was found, suggesting that patterns of age differences varied in relation to the overall comprehension ability of the readers. In the case of "unlike", the 
pattern of results (Figure 3) was similar to the pattern for total competency scores shown in Figure 2. For "unlike" the pattern was more salient for older grades in the high ability group. Both $6^{\text {th }}$ and $9^{\text {th }}$-graders showed significantly more competence than $4^{\text {th }}$-graders. For the word "smaller/larger," the grade by ability interaction failed to reach significance, but the data revealed a pattern of results similar to the word "unlike". However, for the phrase "same as" a different interaction pattern was found (Figure 4). Overall there were no age effects, but a significant grade by ability interaction showed large age effects between the oldest and youngest grades in the middle ability group. Although this interaction pattern varied somewhat from the others, it also supported the predicted greater variability and growth in signaling competency across grades for middle ability readers than for high or low ability readers. Given that competence increases across grade levels were only significant for middle ability readers along with no evidence for maximized competency for the best readers, it is possible that this signal was particularly challenging.

The "same as" signal is in the initial position of an adverbial dependent clause in the last sentence of the two-paragraph text (e.g. "The same as the emperor penguins, Adelie penguins live on Antarctica's pack ice"). Contrary to our findings, McClure and Geva (1983) reported that the initial position in a dependent clause with the conjunctive "although," was easy for $4^{\text {th }}-, 6^{\text {th }}$, and $8^{\text {th }}$-graders and demonstrated no age effects. A difference between this earlier study and our study was the task that participants completed. In McClure and Geva's (1983) study, readers selected among several alternative conjunctions, while in our study readers generated signaling words to complete a cloze. A more important difference was probably the complexity of the materials. The earlier study involved a two-clause sentence while our study involved a two-paragraph text, where the linked information labeled with "same as" required linking the information in the last sentence of the first paragraph about the habitat of one penguin to the last sentence in the second paragraph about the habitat of the other penguin.

Although previous connectives' research has indicated that children's knowledge of connectives varies with regard to the type of relationship expressed (Cain \& Nash, 2oII), our findings suggest that within a particular category of connectives readers' knowledge may vary. Our results suggest that children's knowledge of particular types of text signals may not be constant. In certain contexts, it appears easier for readers to determine which signaling word to use and to apply it appropriately. There may be several reasons for this varying competence in the use of comparative signaling. Readers may possess greater understanding of the meaning of some signaling words in relation to others. However, it's unlikely that variability in performance is due to differences in readers' vocabularies alone, as all four words used in this study were high frequency words to which all students were likely exposed. The difficulty in using some comparative signals in relation to others is likely related to inter- and intra-sentential relationships contained in the text. For those sentences which contain a complex comparative relationship, such as those in 
which two entities are compared or contrasted on a particular issue, it may be more challenging for readers to perceive and label this relationship with the appropriate signaling words. Moreover, those relationships that are represented at the top of the hierarchical structure of the text, organizing the whole text, may be easier for readers to perceive and mark.

The signaling word "different" was the only comparative signal that was not affected by grade level and showed the best usage by the students. As previously mentioned, the differences in scores and patterns of effects for the word "different" versus "unlike" and the other two signals may be due to the type of comparison (global vs. local) and/or overall text organization (comparison at the top of the hierarchical structure vs. more subordinate in the text structure). However, other explanations need further exploration, such as lexical reasons (differential depth of knowledge about the signals; e.g. "different" is a much more frequent word in American English than the other three signaling words [Davies, 20II]), syntactic reasons (subordinate adverbial clauses were the locations for "unlike" and "same as," but not for the other two signals), or local focus between adjacent sentences. McClure and Geva (1983) reported that $4^{\text {th }}$-grade students tended to ignore lexical, syntactic, and discourse constraints, while $8^{\text {th }}$-graders were much more aware of syntactic constraints in the use of the conjunctions "but" and "although" at initial or medial positions within a sentence. In contrast, most, but not all, of the proficient adults in McClure and Geva's (1983) work appeared to be aware of the role of "but" and "although" in marking focus (background vs. foreground), which indicated an understanding of what was most important between adjacent sentences. Also in the McClure and Geva (1983) five-related studies, $4^{\text {th }}$-graders showed good use of "but" and "although" in recognition tasks to mark a comparative relationship, but relied on content (propositional salience) in selecting a sentence that would follow a complex sentence, which contained clauses interrelated by "but" or "although". Instead of using content for this experimental task, the $8^{\text {th }}$-graders paid more attention to form, but just of order/proximity, rather than syntax or lexical alternatives. In our study "unlike" and "same as" were to be generated for the initial words in subordinate clauses. These subordinate clauses provided old/ background information, rather than new topic information that was conveyed by the major clause in the sentence. McClure and Geva (1983) found that both $4^{\text {th }}$ - and $8^{\text {th }}$-graders ignored local focus. Thus, the differential proficiency in use of the four signaling words in our study seems more likely due to differences in global, hierarchical text structure, syntax, or lexical knowledge rather than local focus. Clearly further research is needed in this area.

Our findings suggest that younger readers' ability to correctly perceive and use signaling words may be closely tied to the textual context in which they occur. Previous research with adults has suggested that signaling may be more beneficial with shorter and less complex texts (Lorch, Lorch \& Inman, 1993), as well as texts containing more unfamiliar topics (Lorch \& Lorch, 1996b). When considering the facilitative effect of signaling with children, it is also 
important to consider the type of relationship indicated. Younger readers have more difficulty perceiving more structurally complex text structures (Richgels et al., 1987; Englert \& Hiebert, 1984), and experience more difficulty in marking these relationships with connectives (e.g. Cain, Patson \& Andrews, 2005). It is possible that younger readers may have less sensitivity to text signaling which indicates these relationships. Additional research is needed to determine whether the type of coherence relationships signaled affects the relative benefits of signaling for younger readers.

\subsection{Limitations}

Although the findings from this study can provide insights into developmental differences, caution should be taken in making conclusions about comprehension development based on this cross-sectional comparison of grade levels. It is possible that the differences found in this study are related to cohort differences rather than true developmental patterns. Nevertheless, given that students' performance on the GSRT is similar to students of their age and grade when compared to a normed sample, there is evidence that these students are representative of children of similar ages. Future research, employing a longitudinal design is needed in order to make stronger claims about development.

\subsection{Conclusion}

Younger readers' use of comparative text signaling appears to increase with age for readers of average comprehension ability. Highly skilled readers have such a high level of competency that little improvement may be seen with age, while readers with low comprehension ability may not be able to gain competency given their overall difficulties in comprehending expository texts. It is important to note that no ceiling effects were found. No reading group at any age achieved mastery in their use of comparison signaling. Overall, the results of our study suggest that younger readers' ability to make use of text signaling is related not only to their age, but also to their overall comprehension skill. Future research of children's sensitivity to text signaling must account for these sources of individual differences. Also, the differential patterns across age and ability found in our study for competency in using signals may aid studies adapting instruction about signaling and text structure to the needs of subgroups of students.

\section{References}

Berson, M.J. 2003. United States History: Beginnings. Grade 5. Orlando: Harcourt.

BRidge, C.A. \& Winograd, P.N. 1982. Readers' Awareness of Cohesive Relationships during Cloze Comprehension. Journal of Reading Behavior I4 (3): 299-312.

Cain, K. \& Nash, H.M. 20ir. The Influence of Connectives on Young Readers' Processing and Comprehension of Text. Journal of Educational Psychology I03 (2): 429-44I. 
Cain, K., Patson, N. \& Andrews, L. 2005. Age- and Ability-Related Differences in Young Readers' Use of Conjunctions. Journal of Child Language 32 (4): 877-892.

Davies, M. 20II. Word Frequency Data from the Corpus of Contemporary American English (COCA). Available online: http://www.wordfrequency.info.

Degand, L. \& Sanders, T.J.M. 2002. The Impact of Relational Markers on Expository Text Comprehension in LI and L2. Reading and Writing: An Interdisciplinary Journal I5 (7-8): 739-757.

Duke, N.K. 2000. 3.6 Minutes per Day: The Scarcity of Informational Texts in First Grade. Reading Research Quarterly 35 (2): 202-224.

Englert, C.S. \& Hiebert, E.H. 1984. Children's Developing Awareness of Text Structures in Expository Materials. Journal of Educational Psychology 76 (I): 65-74.

Flesch, R. 1948. A New Readability Yardstick. Journal of Applied Psychology 32 (3): 22I-233.

Geva, E. \& Ryan, E.B. 1985. Use of Conjunctions in Expository Texts by Skilled and Less Skilled Readers. Journal of Reading Bebavior 17 (4): 331-346.

Halliday, M.A.K. \& Hasan, R. 1976. Cohesion in English. London: Longman.

Kamalski, J., Sanders, T.J.M. \& Lentz, L. 2008. Coherence Marking, Prior Knowledge, and Comprehension of Informative and Persuasive Texts: Sorting Things Out. Discourse Processes 45 (4-5): 323-345.

Kardash, C.M. \& Noel, L.K. 2000. How Organizational Signals, Need for Cognition, and Verbal Ability Affect Text Recall and Recognition. Contemporary Educational Psychology 25 (3): 317-33I.

KInTsCH, W. 2004. Chapter XLVI: The Construction-Integration Model of Text Comprehension and its Imprecations for Instruction. In R.B. RudDELl \& N.J. UNRAU (eds), Theoretical Models and Processes of Reading. Newark: International Reading Association: I270-I327 [ $5^{\text {th }}$ edition].

Lemarié, J. et al. 2008. SARA: A Text-Based and Reader-Based Theory of Signaling. Educational Psychologist 43 (I): 27-48.

Loman, N.L. \& MaYer, R.E. 1983. Signaling Techniques that Increase the Understandability of Expository Prose. Journal of Educational Psychology 75 (3): 402- 4I2.

LoRCH, R.F. Jr. 1989. Text-Signaling Devices and Their Effects on Reading and Memory Processes. Educational Psychology Review I (3): 209-234.

Lorch, R.F. Jr. et al. 20oI. Effects of Headings on Text Summarization. Contemporary Educational Psychology 26 (2): I7I-19I.

Lorch, R.F. Jr. \& Lorch, E.P. 1985. Topic Structure Representation and Text Recall. Journal of Educational Psychology 77 (2): I37-I48.

LoRCH, R.F. Jr. \& LorCH, E.P. 1996a. Effects of Organizational Signals on Free Recall of Expository Text. Journal of Educational Psychology 88 (I): 38-48.

LoRCH, R.F. Jr. \& LorCH, E.P. 1996b. Effects of Headings on Text Recall and Summarization. Contemporary Educational Psychology 2I (3): 26I-278.

Lorch, R.F. Jr., Lorch, E.P. \& InMAN, W.E. 1993. Effects of Signaling Topic Structure on Text Recall. Journal of Educational Psychology 85 (2): 28I-290. 
Mayer, R.E., Dyck, J.L. \& CoOK, L.K. I984. Techniques that Help Readers Build Mental Models from Scientific Text: Definitions Pretraining and Signaling. Journal of Educational Psychology 76 (6): I089-IIO5.

McClure, E. \& Geva, E. 1983. The Development of the Cohesive Use of Adversative Conjunctions in Discourse. Discourse Processes 6 (4): 4II-432.

Meyer, B.J.F. 1975. The Organization of Prose and its Effects on Memory. Amsterdam: North-Holland Pub. Co.

Meyer, B.J.F. 1985a. Chapter III: Signaling the Structure of Text. In D.H. Jonassen (ed.), The Technology of Text. Englewood Cliffs (N.J.): Educational Technology: 64-89.

Meyer, B.J.F. 1985b. Chapter II: Prose Analysis: II-64. Chapter X: Purposes, Procedures, and Problems: 269-304. In B.K. Britton \& J.B. Black (eds), Analyzing and Understanding Expository Text. Hillsdale (N.J.): Lawrence Erlbaum.

Meyer, B.J.F., Brandt, D.M. \& Bluth, G.J. 1980. Use of Top-Level Structure in Text: Key for Reading Comprehension of Ninth-Grade Students. Reading Research Quarterly I6 (I): 72-IO3.

Meyer, B.J.F. et al. 1998. Interest and Strategies of Young and Old Readers Differentially Interact with Characteristics of Texts. Educational Gerontology 24 (8): 747-77I.

MeYer, B.J.F. et al. 2oIo. Web-Based Tutoring of the Structure Strategy With or Without Elaborated Feedback or Choice for Fifth- and Seventh-Grade Readers. Reading Research Quarterly 45 (I): 62-92.

Meyer, B.J.F. \& Poon, L.W. 200I. Effects of Structure Strategy Training and Signaling on Recall of Text. Journal of Educational Psychology 93 (I): I4I-I59.

Meyer, B.J.F. \& Rice, G.E. 1989. Prose Processing in Adulthood: The Text, the Reader, and the Task. In L.W. Poon, D.C. Rubin \& B.A. Wilson (eds), Everyday Cognition in Adulthood and Later Life. Cambridge: Cambridge University Press: I57-I94.

MeYer, B.J.F., Wijekumar, K.K. \& Lin, Y. 2OII. Individualizing a Web-Based Structure Strategy Intervention for Fifth Graders' Comprehension of Nonfiction. Journal of Educational Psychology I03 (I): I40-I68.

Naumann, J. et al. 2007. Signaling in Expository Hypertexts Compensates for Deficits in Reading Skill. Journal of Educational Psychology 99 (4): 79I-807.

Ohlhausen, M.M. \& Roller, C.M. 1988. The Operation of Text Structure and Content Schemata in Isolation and in Interaction. Reading Research Quarterly 23 (I): 70-88.

Peterson, C. 1986. Semantic and Pragmatic Uses of "But". Journal of Child Language I3 (3): $583-590$.

Rapp, D.N. et al. 2007. Higher-Order Comprehension Processes in Struggling Readers: A Perspective for Research and Intervention. Scientific Studies of Reading II (4): 289-3I2.

Rescorla, L. \& Rosenthal, A.S. 2004. Growth in Standardized Ability and Achievement Test Scores from $3^{\text {rd }}$ to ${ }^{\text {th }}{ }^{\text {th }}$ Grade. Journal of Educational Psychology 96 (I): 85-96.

Richgels, D.J. et al. 1987. Awareness of Four Text Structures: Effects on Recall of Expository Text. Reading Research Quarterly 22 (2): 177-196.

Ritchey, K., Schuster, J. \& Allen, J. 2008. How the Relationship between Text and Headings Influences Readers' Memory. Contemporary Educational Psychology 33 (4): 859-874. 
Rossi, J.P. 1990. The Function of Frame in the Comprehension of Scientific Text. Journal of Educational Psychology 82 (4): 727-732.

SANDERS, T.J.M. 1997. Semantic and Pragmatic Sources of Coherence: On the Categorization of Coherence Relations in Context. Discourse Processes 24 (I): I19-I47.

Sanders, T.J.M., Spooren, W.P.M. \& Noordman, L.G.M. 1992. Toward a Taxonomy of Coherence Relations. Discourse Processes I5 (I): I-35.

Shaywitz, B.A. et al. 1995. A Matthew Effect for IQ but Not for Reading: Results from a Longitudinal Study. Reading Research Quarterly 30 (4): 894-906.

SPOoREn, W.P.M. \& SANDERS, T. J.M. 2008. The Acquisition Order of Coherence Relations: On Cognitive Complexity in Discourse. Journal of Pragmatics 40 (12): 2003-2026.

Stanovich, K.E. 1986. Matthew Effects in Reading: Some Consequences of Individual Differences in the Acquisition of Literacy. Reading Research Quarterly 2I (4): 360-407.

Test Your Document's Readability. 2007. In Microsoft Office Online. URL: http:// office.microsoft.com/en-us/help/HPior48506ro33.aspx.

VAn den Broek, P. et al. 2004. Chapter XLV: The Landscape Model of Reading: Inferences and the Online Construction of a Memory Representation. In R.B. Ruddell \& N.J. Unrau (eds), Theoretical Models and Processes of Reading. Newark: International Reading Association: $1249^{-1269}$ [ $5^{\text {th }}$ edition].

Vauras, M., Kinnunen, R. \& Kuusela, L. 1994. Development of Text-Processing Skills in High-, Average-, and Low-Achieving Primary School Children. Journal of Reading Behavior 26 (4): 36I-389.

Wiederholt, J.L. \& Blalock, G. 2000. Gray Silent Reading Tests. Austin: PRO-ED.

ZINAR, S. 1990. Fifth-Graders' Recall of Propositional Content and Causal Relationships from Expository Prose. Journal of Reading Behavior 22 (2): 181-199. 